\title{
Effects of Apigenin on the Expressions of TGF- $\beta 1 R$ II, NF-kB and VEGF Genes in Tumor Tissues of Mice with H29 Colon Cancer
}

\author{
Na Yi ${ }^{1}$, Lengge $\mathrm{Si}^{2}$, Yuehong Wang ${ }^{2}$, Lidao Bao ${ }^{1,}$ * \\ ${ }^{1}$ College of Pharmacy, Inner Mongolia Medical University, Hohhot, China \\ ${ }^{2}$ College of Mongolian Medicine, Inner Mongolia Medical University, Hohhot, China
}

\section{Email address:}

349881704@qq.com (Na Yi), baolidao237@qq.com (Lidao Bao)

\section{To cite this article:}

$\mathrm{Na}$ Yi, Lengge Si, Yuehong Wang, Lidao Bao. Effects of Apigenin on the Expressions of TGF- $\beta 1 \mathrm{R}$ II, NF- $\mathrm{kB}$ and VEGF Genes in Tumor Tissues of Mice with $\mathrm{H} 29$ Colon Cancer. American Journal of Clinical and Experimental Medicine. Vol. 3, No. 6, 2015, pp. 378-382. doi: 10.11648/j.ajcem.20150306.20

\begin{abstract}
To observe the effects of Apigenin on the expressions of TGF- $\beta 1 \mathrm{R}$ II, NF- $\mathrm{KB}$ and VEGF genes in tumor tissues of mice with H29 colon cancer. Fifty ICR mice with H29 colon cancer were randomly divided into five groups: normal saline group, low-dose Apigenin group, middle-dose Apigenin group and high-dose Apigenin group and cyclophosphamide group. The mice were killed on the next day of administration discontinuance, and subcutaneous tumor tissues were collected. Quantitative fluorescence RT-PCR was used to detect the expression of TGF- $\beta 1$ R II, NF- $\kappa$ B and VEGF genes in tumor tissues of H29 colon cancer mice. Apigenin raised the expression level of TGF- $\beta 1$ R II in H29 colon cancer tissues, which showed the most obvious effect in the middle-dose group, with a significant difference compared with the normal saline group ( $\mathrm{P}<0.01)$. The Apigenin group of each dose could significantly lower the NF- $\kappa \mathrm{B}$ expression level in $\mathrm{H} 29$ colon solid tumors, showing significant differences compared with the normal saline group $(\mathrm{P}<0.01)$. The middle-dose and high-dose Apigenin groups could significantly reduce the level of VEGF expression in tumor tissues of ICR mice with H29 colon cancer, and the high-dose group had most obvious effect, and there were significant difference among the middle-dose group, high-dose group and the normal saline group $(\mathrm{P}<0.01)$. The mechanism of anti-tumor effect of Apigenin might be the reason that Apigenin can raise the expression level of TGF- $\beta 1 \mathrm{R}$ II by down-regulating the expression of NF- $\kappa \mathrm{B}$ and VEGF in tumor tissues of tumor-bearing mice, thereby inhibiting tumor angiogenesis and tumor cell proliferation, so as to achieve the anti-tumor effect.
\end{abstract}

Keywords: Apigenin, H29 Colon Cancer, TGF- $\beta 1$ RII, NF- $\kappa$ B, VEGF

\section{Background}

The antitumor effect of Apigenin has many complicated mechanisms [1]. Studies have shown that Apigenin can selectively inhibit the activities of fatty acid synthase of prostate and breast cancer cells, which is related with the growth and apoptosis of anti-tumor cells; Apigenin can significantly reduce the incidence of dimethyl hydrazine-induced colon cancer as well as the size of the tumor, its regulation of lipid peroxidation, antioxidant, antiproliferative effects [2-4]; Apigenin can inhibit the migration and invasion of VEGF of ovarian cancer cells in an in vitro dose-dependent way, which is related with the reason that it can inhibit the secretion of matrix metalloproteinase -9 (MMP-9) and down-regulate the expression of extracellular signal-regulated kinase 2 (ERK2) [5, 6]. Preliminary studies $[7,8]$ have shown that Apigenin has a significant inhibitory effect on mice with $\mathrm{H} 29$ colon cancer and S180 sarcoma tumor, the exact mechanism, however, has not been yet clear. This study evaluated the effect of Apigenin on the expression of TGF- $\beta 1 \mathrm{R}$ II, NF- $\kappa \mathrm{B}$ and VEGF genes in H29 colon tumor tissues using quantitative fluorescence PCR, to further explore its molecular mechanism so as to provide experimental evidence for the clinical applications of this medicine.

\section{Materials and Methods}

\subsection{Animals and Cell Line}

H29 colon cancer cell strains; SPF ICR mice aged 4 to 6 weeks old and weighing 16 to $20 \mathrm{~g}$ were purchased from the 
Shanghai Laboratory Animal Research Center, Chinese Academy of Sciences and raised in the Experimental Animal Center of our hospital.

\subsection{Drugs}

Apigenin was home-made according to the prescription and preparation process of the Traditional Chinese Medicine Preparation Room of our hospital. Its concentration was calculated by the weight of crude drug put, and the concentration of finished drug was $1.5 \mathrm{~g} / \mathrm{mL}$, and use concentration was prepared according to the dosage and volume of administration. Cyclophosphamide (CTX) for injection (batch No.: 9F586E) was bought from Baxter Oncology Gmbh (Germany).

\subsection{Reagents}

TRIzol reagent was purchased from Reagent (USA); quantitative fluorescence RT-PCR detection kits for mice TGF- $\beta 1 \mathrm{R}$ II, NF- $\mathrm{BB}$ and VEGF were purchased from Guangzhou Dahui Biotech Co., Ltd.

\subsection{Model Establishment, Grouping and Administration Methods}

Fifty ICR male mice with the body weight of $(18 \pm 2) \mathrm{g}$ were included in this study. Ascites of mice inoculated with H29 tumor cell strains for 6 to 8 days was taken under sterile conditions (milky thick ascites tumor fluid, discarded if the color was yellow or red), diluted with normal saline to adjust the cell concentration to $1 \times 10^{7} / \mathrm{mL}$, and then inoculated subcutaneously in the axilla of the left forelimb of mouse, 0.2 $\mathrm{mL}$ for each. The mice were randomly divided into five groups: positive control group, negative control group, low-dose Apigenin group, middle-dose Apigenin group and high-dose Apigenin group $(n=10)$. Twenty-four hours after inoculation, the negative control group was given intragastric administration with $0.2 \mathrm{~mL} / 10 \mathrm{~g}$ normal saline, once a day; the positive control group was given intraperitoneal injection with $20 \mathrm{mg} / \mathrm{kg}$ CTX, once a day. The low-dose, middle-dose and high-dose Apigenin groups were orally administered with Apigenin stock solution $(25 \mathrm{~g} / \mathrm{kg}), \quad$ Apigenin twice-concentrated solution $(50 \mathrm{~g} / \mathrm{kg})$, Apigenin fourfold-concentrated solution $(100 \mathrm{~g} / \mathrm{kg})$ respectively, 0.2 $\mathrm{mL} / 10 \mathrm{~g}$, once a day. All administration was discontinued 10 days later. The mice were killed on the next day of the discontinuance, and subcutaneous tumor was peeled, quickly stored in liquid nitrogen, and transferred to $-70^{\circ} \mathrm{C}$ low-temperature refrigerator for standby use.

\subsection{Quantitative Fluorescence RT-PCR Detection}

(1) Extraction of total tumor mRNA: 1) Take 50-100 mg tumor tissue stored in $-70^{\circ} \mathrm{C}$ low-temperature refrigerator, place it in $2.0 \mathrm{~mL}$ centrifuge tube, add $1 \mathrm{~mL}$ Trizol for full homogenate and stand statically at room temperature for $5 \mathrm{~min}$. 2) Add $0.2 \mathrm{~mL}$ chloroform, oscillate for $20 \mathrm{~s}$, and stand for 2 min. (3) Centrifuge at $4^{\circ} \mathrm{C}$ and $12,000 \mathrm{r} / \mathrm{min}$ for $15 \mathrm{~min}$, and then take the supernatant. 4) Add $1.0 \mathrm{~mL}$ isopropanol, fully mix the liquid in tube gently, and stand statically at room temperature for $10 \mathrm{~min}$. 5) Centrifuge at $4^{\circ} \mathrm{C}$ and $12,000 \mathrm{r} / \mathrm{min}$ for $10 \mathrm{~min}$, then discard the supernatant. 6) Add $1 \mathrm{~mL} 75 \%$ ethanol to gently wash precipitation. Centrifuge at $4{ }^{\circ} \mathrm{C}$ and 7,500 $\mathrm{r} / \mathrm{min}$ for $10 \mathrm{~min}$, then discard the supernatant. 7) Dry by airing, then add an appropriate amount of $\mathrm{DEPCH} 2 \mathrm{O}$ for dissolution (promoting dissolution at $65^{\circ} \mathrm{C}$ for 10 to $15 \mathrm{~min}$ ). 8) Measure RNA content and purity by UV spectrophotometer $\left(\mathrm{OD}_{260}\right)$. 9) Placed the product in $-70^{\circ} \mathrm{C}$ refrigerator for standby use.

(2) Reverse transcription reaction: The reaction was performed according to the kit instructions. Reaction conditions: $37^{\circ} \mathrm{C}$ for $60 \mathrm{~min}, 95^{\circ} \mathrm{C}$ for $3 \mathrm{~min}$.

(3) Real-time PCR amplification: The reaction was performed according to the kit instructions. Reaction conditions: $93^{\circ} \mathrm{C} \rightarrow$ denaturation for $3 \mathrm{~min}$, then $93^{\circ} \mathrm{C}$ for $45 \mathrm{~s}$ $\rightarrow 55^{\circ} \mathrm{C}$ for $60 \mathrm{~s}$ for 40 cycles in total.

(4) PCR primer sequences of TGF- $\beta 1 \mathrm{R}$ II:

Forward Primer: 5'-GGCCGTCACCCAACGTTCA -3' Reverse Primer: 5'-AGCGCGCTCTAATAGTTCCCC-3' Probe Primer:

5'-CTCGCGGTCGGATAACGGATCCAC-3'

$\mathrm{NF}-\kappa \mathrm{B}$ :

Forward Primer: 5'-ACCTCTAAAGGTGGAAGC-3'

Reverse Primer: 5'-TCACGGCGAGTACCCGAC-3'

Probe Primer: 5'-CAATGCCGGTGGCCGTCAGTAC-3'

VEGF:

Forward Primer: 5'-CGTACCACCTCGCGCCAA-3'

Reverse Primer: 5'-GAGAACTTGGCGGCAGACA-3'

Probe

Primer: 5'-CCTGCCGACGGAGCGGGAAGATCAC-3'

(5) Analysis of results Positive standard points were selected for analysis, and if the correlation coefficient $\mathrm{R}^{2}$ was larger than 0.96 , it could be considered to have a good linear relation to determine the quantitative standard curve; absolute quantitative values of the fluorescence quantitative reaction of samples (cDNA concentration copy number/ $\mu \mathrm{L}$ ) were obtained according to the standard curve.

\subsection{Statistical Analysis}

All data were analyzed by SPSS 17.0. The measurement data were expressed as $\mathrm{X} \pm S$, and the differences between two groups were subjected to $t$ test.

\section{Results}

\subsection{Effects of Apigenin on TGF-ß1R II mRNA Expression}

The standard curve of quantitative fluorescence RT-PCR was as follows: $\mathrm{Y}=-3.8371 \mathrm{LgX}+44.2261, \mathrm{R}^{2}=0.998$. The standard curve was in line with the instructions provided for the correlation coefficient $\mathrm{R}^{2}>0.96$, showing a good linear relationship (Figure 1). 


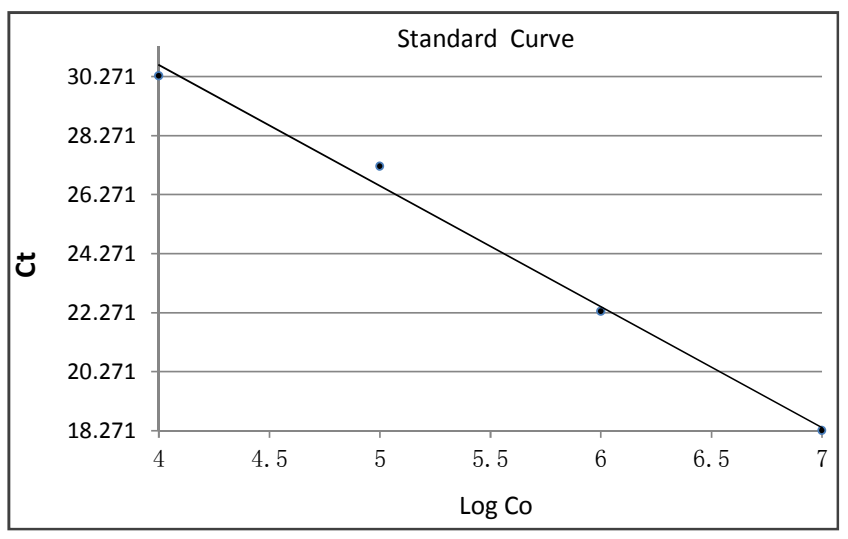

Figure 1. Standard curves of TGF- $\beta 1 R$ II expression.

According to the standard curve of TGF- $\beta 1 \mathrm{R}$ II expression in tumor tissues of mice with $\mathrm{H} 29$ colon cancer, the expression of TGF- $\beta 1 \mathrm{R}$ II was the highest in the middle-dose group, followed by the high-dose group, and was the lowest in the CTX group; the TGF- $\beta 1 \mathrm{R}$ II expression in the low-dose group was similar to that in the normal saline control group, which was the lowest; There were significant differences among the middle-dose group, high-dose group, CTX chemotherapy group and the normal saline control group $(\mathrm{P}<0.01)$.

Quantitative fluorescence RT-PCR detection results of TGF- $\beta 1 \mathrm{R}$ II in the tumor tissues are listed in Table 1.

Table 1. Quantitative fluorescence RT-PCR detection results of TGF- $\beta 1 R$ II in the tumor tissues $(n=10, X \pm S)$.

\begin{tabular}{lll}
\hline Group & Dose & $\begin{array}{l}\text { cDNA concentration copy } \\
\text { number }(\boldsymbol{\mu L} \mathbf{L})\end{array}$ \\
\hline Normal saline group $20 \mathrm{~mL}$ & $20 \mathrm{ml} / \mathrm{kg}$ & $2302.1 \pm 1137.6$ \\
Low-dose group $20 \mathrm{~g}$ & $25 \mathrm{ml} / \mathrm{kg}$ & $2815.2 \pm 1107.4$ \\
Middle-dose group $40 \mathrm{~g}$ & $40 \mathrm{ml} / \mathrm{kg}$ & $21036.1 \pm 11528.8^{\mathbf{\Delta}}$ \\
High-dose group $80 \mathrm{~g}$ & $100 \mathrm{ml} / \mathrm{kg}$ & $16596.2 \pm 11089.8^{\mathbf{\Delta}}$ \\
CTX & $30 \mathrm{mg} / \mathrm{kg}$ & $6772.5 \pm 1123.9^{\mathbf{\Delta}}$ \\
\hline
\end{tabular}

Compared with the normal saline group, ${ }^{*} \mathrm{P}<0.05, \Delta \mathrm{P}<0.01$.

\subsection{Effects of Apigenin on NF-kB mRNA Expression}

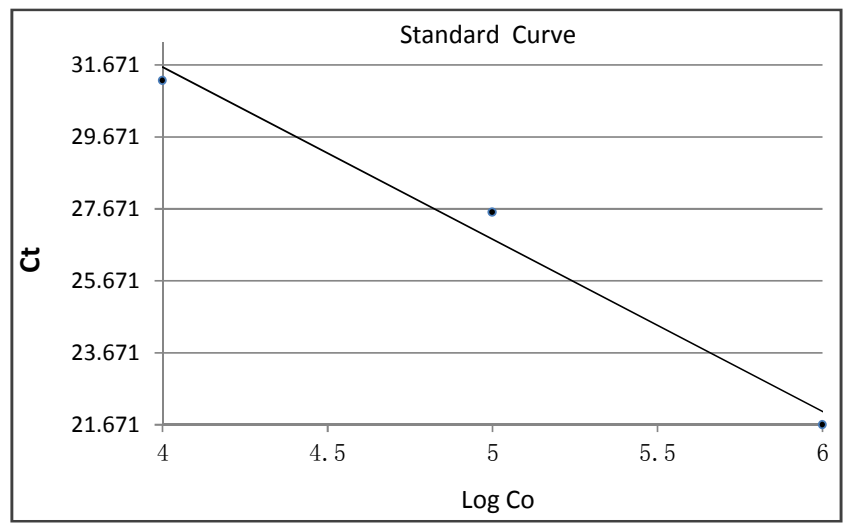

Figure 2. Standard curves of $N F-\kappa B$ expression.

The standard curve of quantitative fluorescence RT-PCR was as follows: $\mathrm{Y}=-3.6825 \mathrm{LgX}+44.4907, \mathrm{R}^{2}=0.997 . \mathrm{R}^{2}=0$.
998. The standard curve was in line with the instructions provided for the correlation coefficient $\mathrm{R}^{2}>0.96$, showing a good linear relationship (Figure 2).

The order for the NF- $\mathrm{B}$ expression level of each group was as follows: normal saline group $>$ low-dose group $>$ middle-dose group $>$ CTX chemotherapy group $>$ high-dose group. There were significant differences among the low-dose group, middle-dose group, high-dose group, CTX group and the normal saline control group $(\mathrm{P}<0.05)$. The difference between the high-dose group and the CTX chemotherapy group was statistically significant $(\mathrm{P}<0.05)$ (Table 2).

Table 2. Quantitative fluorescence RT-PCR detection results of $N F-\kappa B$ in the tumor tissues $(n=10, X \pm S)$.

\begin{tabular}{lll}
\hline Group & Dose & $\begin{array}{l}\text { cDNA concentration copy } \\
\text { number }(\boldsymbol{\mu} \mathbf{L})\end{array}$ \\
\hline Normal saline group $20 \mathrm{~mL}$ & $20 \mathrm{ml} / \mathrm{kg}$ & $512698.1 \pm 14563.2$ \\
Low-dose group $20 \mathrm{~g}$ & $25 \mathrm{ml} / \mathrm{kg}$ & $17234.8 . \pm 10896.7^{\mathbf{\Delta}}$ \\
Middle-dose group $40 \mathrm{~g}$ & $40 \mathrm{ml} / \mathrm{kg}$ & $51369.1 \pm 14563.8^{\mathbf{\Delta}}$ \\
High-dose group $80 \mathrm{~g}$ & $100 \mathrm{ml} / \mathrm{kg}$ & $4469.2 \pm 2173.8^{\mathbf{\Delta}}$ \\
CTX & $30 \mathrm{mg} / \mathrm{kg}$ & $19653.5 \pm 2123.9^{\mathbf{\Delta}}$ \\
\hline
\end{tabular}

Compared with the normal saline group, $* \mathrm{P}<0.05, \boldsymbol{\Delta} \mathrm{P}<0.01$.

\subsection{Effects of Apigenin on VEGF mRNA Expression}

The standard curve of quantitative fluorescence RT-PCR was as follows: $\mathrm{Y}=-3.3491 \mathrm{LgX}+41.8125, \mathrm{R}^{2}=0.988 . \mathrm{R}^{2}=0$. 998. The standard curve was in line with the instructions provided for the correlation coefficient $\mathrm{R}^{2}>0.96$, showing a good linear relationship (Figure 3).

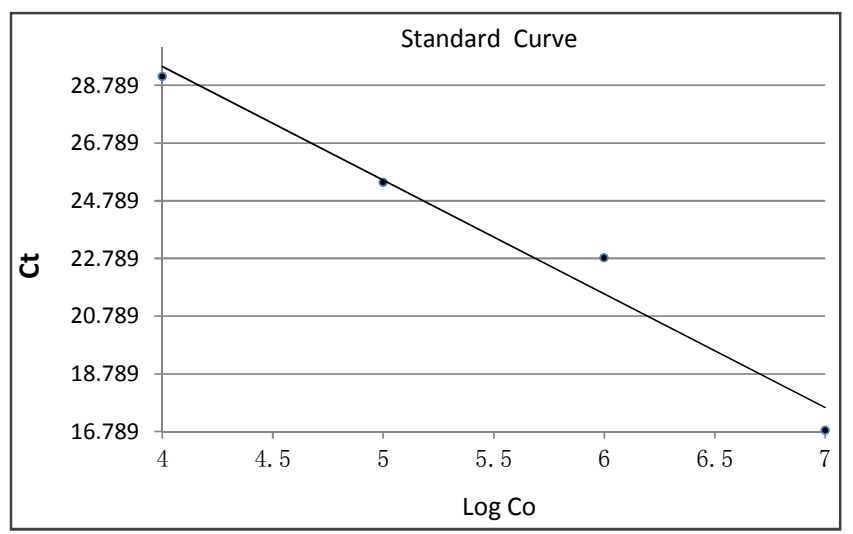

Figure 3. Standard curves of VEGF expression.

The expression of VEGF was the highest in the negative control group, followed by the low-dose and middle-dose Apigenin groups, and the lowest in the high-dose Apigenin group and CTX positive control group, the results of which were similar; there were statistically significant differences among the high-dose Apigenin group, CTX chemotherapy group and the normal saline group $(\mathrm{P}<0.01)$, and no significant difference was found between the high-dose Apigenin group and the CTX chemotherapy group $(\mathrm{P}>0.05)$ (Table 3). 
Table 3. Quantitative fluorescence RT-PCR detection results of VEGF in the tumor tissues $(n=10, X \pm S)$.

\begin{tabular}{lll}
\hline Group & Dose & $\begin{array}{l}\text { cDNA concentration copy } \\
\text { number }(\boldsymbol{\mu L} \mathbf{L})\end{array}$ \\
\hline Negative control group & $20 \mathrm{ml} / \mathrm{kg}$ & $19346.1 \pm 7635.2$ \\
Low-dose group & $25 \mathrm{ml} / \mathrm{kg}$ & $13779.8 \pm 2337.7$ \\
Middle-dose group & $40 \mathrm{ml} / \mathrm{kg}$ & $8013.1 \pm 3001.8^{\mathbf{\Lambda}}$ \\
High-dose group & $100 \mathrm{ml} / \mathrm{kg}$ & $5189.2 \pm 1326.8^{\mathbf{\Lambda}}$ \\
Positive control group & $30 \mathrm{mg} / \mathrm{kg}$ & $3896.5 \pm 1789.9^{\mathbf{\Lambda}}$ \\
\hline
\end{tabular}

Compared with the normal saline group, ${ }^{*} \mathrm{P}<0.05, \mathbf{\Delta} \mathrm{P}<0.01$.

\section{Discussion}

With the development of genomics and proteomics technology, great progress has been made in the early detection, postoperative recurrence and metastasis monitoring of colon cancer. The occurrence and development of colon cancer is closely related with the over-expression of a variety of growth factors (IGF-II, NF- $\kappa \mathrm{B}$, VEGF, TGF- $\beta 1$ and HGF). Early experiments have showed that Apigenin has a significant inhibitory effect on mice with H29 colon cancer and S180 sarcoma tumor; low-, medium- and high-dose groups can all prolong the survival days of mice with H29 colon cancer and ascites tumor, and down-regulate the expression of CyclinD1 mRNA in tumor tissues of tumor-bearing mice. By detection, this study further explored the effect of Apigenin on the expression of TGF- $\beta 1 \mathrm{R}$ II, $\mathrm{NF}-\kappa \mathrm{B}$ and VEGF genes of mice with $\mathrm{H} 29$ colon tumor.

TGF- $\beta$, as a multifunctional cytokine, plays an important role in cell cycle regulation, wound healing, angiogenesis, cell growth and differentiation and cell apoptosis, etc. [9, 10]. The tumor suppressor role of TGF- $\beta 1$ is achieved through inhibiting cell growth and promoting differentiation. Activated TGF- $\beta 1$ functions through the mediation of its corresponding receptors $[11,12]$. It has been reported in the literature that decreased expression of transforming growth factor (TGF) $\beta 1$ type II receptor (TGF- $\beta 1 \mathrm{R}$ II) is due to the reason that the body cells escape the negative regulation on TGF- $\beta 1$ growth, leading to uncontrolled proliferation and such an important change as canceration. Studies [11, 13-15] have found that compared with chronic colitis or colon fibrosis patients, the TGF- $\beta 1 \mathrm{R}$ II expression of colon cancer patients is significantly reduced, and meanwhile the expression of TGF- $\beta 1 \mathrm{R}$ II in colon cancer tissues is significantly lower than that in normal tissues, while the TGF- $\beta 1 \mathrm{R}$ II expression is higher in colon cancer tissues with high differentiation, small tumor, poor metastasis and long interval of recurrence $(\mathrm{P}<0.05)$. It indicates that the expression of TGF- $\beta 1 \mathrm{R}$ II in colon cancer tissues is decreased, leading to negative regulatory disorder of colon cancer cells, which might be one of the important factors of colon carcinogenesis; the expression of TGF- $\beta 1 \mathrm{R}$ II was negatively correlative with malignant progression of colon cancer, with a potential significance to the treatment of colon cancer.

Nuclear transcription factor $(\mathrm{NF}-\kappa \mathrm{B})$ is involved in many aspects of the occurrence and development of colon cancer, such as blocking apoptosis and promoting cell proliferation, mediating gene expression related to tumor development, angiogenesis and metastasis, promoting tumor cell invasion and dissemination as well as the generation of tumor drug resistance, and it is also a major factor that regulates the synthesis of TGF- $\beta$ [16-19]. This study found that the NF- $\kappa B$ gene showed significantly high expression in colon cancer tissues, suggesting that it might play the role of oncogenes in the occurrence and development process of colon cancer.

VEGF (vascular endothelial growth factor), as a major pro-angiogenic factor in tumor tissues, can directly stimulate the proliferation of endothelial cells by specific receptors on them, to produce the plasminogen activator and collagenase, etc., increase vascular permeability, and promote plasma fibrinogen extravasation. This can not only promote the migration of endothelial cells, helping angiogenesis, but also be conducive to tumor cell shedding, invasion or diffusion to adjacent matrix of fibrous and connective tissues, so as to create the conditions for tumor invasion and metastasis [19-21]. Colon cancer is a malignant tumor with rich blood supply and high metastasis, and its tumor angiogenesis, proliferation, invasion and metastasis are closely related to VEGF [22-26]. Studies have shown that the expression rates of VEGF in colon cancer, non-encapsulated HCC and colon cancer with extra-colon metastasis are $63.9 \%, 78.3 \%$ and $90.9 \%$ respectively. Under the action of high expression of VEGF, colon cancer tissues can produce a large number of tumor vessels, and meanwhile VEGF can also enhance capillary permeability, thereby increasing blood perfusion in tumor tissues. The experimental results showed that the Apigenin group of each dose could raise the TGF- $\beta 1 \mathrm{R}$ II gene expression and decrease the expression of $\mathrm{NF}-\kappa \mathrm{B}$ and VEGF genes. This prompts that the anti-tumor effect of Apigenin is multi-channel and multi-target, which can not only affect the cycle regulatory factors of tumor cells, but also inhibit tumor angiogenesis and tumor cell proliferation by regulating factors related to vessels, ultimately achieving its anti-tumor effect. It needs to be studied further on the in-depth mechanism of the anti-tumor effect of Apigenin.

\section{Conclusion}

The study concluded that the mechanism of anti-tumor effect of Apigenin might be the reason that Apigenin can raise the expression level of TGF- $\beta 1 \mathrm{R}$ II by down-regulating the expression of $\mathrm{NF}-\kappa \mathrm{B}$ and VEGF in tumor tissues of tumor-bearing mice, thereby inhibiting tumor angiogenesis and tumor cell proliferation, so as to achieve the anti-tumor effect.The results of this experiment provide experimental basis for the clinical application of this medicine.

\section{References}

[1] Park SW, Cho CS, Jun HO, et al. Anti-angiogenic effect of Apigenin on retinal neovascularization via blockade of reactive oxygen species production. Invest Ophthalmol Vis Sci, 2012, 19: 7718-7726. 
[2] Lim do Y, Cho HJ, Kim J, et al. Apigenin decreases IGF-II production and downregulates insulin-like growth factor-I receptor signaling in ht-29 human colon cancer cells. BMC Gastroenterol, 2012, 23: 9.

[3] Pandurangan AK, Dharmalingam P, Ananda Sadagopan SK, et al. Effect of Apigenin on the levels of glycoproteins during azoxymethane-induced colon carcinogenesis in mice. Asian Pac J Cancer Prev, 2012, 13: 1569-1573.

[4] Markaverich B, AlejandroM. Bioflavonoids, type II [H-3] estradiol binding sites and prostatic cancer cell proliferation. Int J Oncol, 1997, 11: 6.

[5] Gates MA, Tworoger SS, Hecht JL, et al. A prospective study of dietary flavonoid intake and incidence of epithelial ovarian cancer. Int J Cancer, 2007, 121: 2225-2232.

[6] Chen SS, Michael A, Butler-Manuel SA. Advances in the treatment of ovarian cancer: A potential role of antiinflammatory phytochemicals. Discov Med, 2012, 13: 7-17.

[7] Lim do Y, Jeong Y, Tyner AL, et al. Induction of cell cycle arrest and apoptosis in ht-29 human colon cancer cells by the dietary compound Apigenin. Am J Physiol Gastrointest Liver Physiol, 2007, 292: G66-75.

[8] Xie YY, Yuan D, Yang JY, et al. Cytotoxic activity of flavonoids from the flowers of chrysanthemum morifolium on human colon cancer colon205 cells. J Asian Nat Prod Res, 2009, 11: 771-778.

[9] Keku TO, Vidal A, Oliver S, et al. Genetic variants in IGF-I, IGF-II, IGFBP-3, and adiponectin genes and colon cancer risk in african americans and whites. Cancer Causes Control, 2012, 23: $1127-1138$.

[10] Kyle AH, Baker JH, Minchinton AI. Targeting quiescent tumor cells via oxygen and igf-i supplementation. Cancer Res, 2012, 72: 801-809.

[11] Li F, Cao Y, Townsend C M, Jr., et al. Tgf-beta signaling in colon cancer cells. World J Surg, 2005, 29: 306-311.

[12] Markowitz S, Wang J, Myeroff L, et al. Inactivation of the type II TGF-beta receptor in colon cancer cells with microsatellite instability. Science, 1995, 268: 1336-1338.

[13] Becker C, Fantini M C, Schramm C, et al. TGF-beta suppresses tumor progression in colon cancer by inhibition of il-6 trans-signaling. Immunity, 2004, 21: 491-501.

[14] Bellam N, Pasche B. TGF-beta signaling alterations and colon cancer. Cancer Treat Res, 2010, 155: 85-103.
[15] Dornhoff H, Becker C, Wirtz S, et al. A variant of smurf2 protects mice against colitis-associated colon cancer by inducing transforming growth factor beta signaling. Gastroenterology, 2012, 142: 1183-1194 e4.

[16] Nakagawa Y, Akao Y. Fhit protein inhibits cell growth by attenuating the signaling mediated by nuclear factor-kappab in colon cancer cell lines. Exp Cell Res, 2006, 312: 2433-2442.

[17] Okayama T, Kokura S, Ishikawa T, et al. Antitumor effect of pretreatment for colon cancer cells with hyperthermia plus geranylgeranylacetone in experimental metastasis models and a subcutaneous tumor model of colon cancer in mice. Int $\mathrm{J}$ Hyperthermia, 2009, 25: 141-149.

[18] Seufert B L, Poole E M, Whitton J, et al. IkappabкBeta and nfkappab1, nsaid use and risk of colorectal cancer in the colon cancer family registry. Carcinogenesis, 2013, 34: 79-85.

[19] Yun J W, Lee W S, Kim M J, et al. Characterization of a profile of the anthocyanins isolated from vitis coignetiae pulliat and their anti-invasive activity on ht-29 human colon cancer cells. Food Chem Toxicol, 2010, 48: 903-909.

[20] Yonezawa M, Wada K, Tatsuguchi A, et al. Heregulin-induced vegf expression via the erbb3 signaling pathway in colon cancer. Digestion, 2009, 80: 215-225.

[21] Zhang Y, Liu X, Zhang J, et al. The expression and clinical significance of pi3k, pakt and vegf in colon cancer. Oncol Lett, 2012, 4: 763-766.

[22] Adachi S, Yasuda I, Nakashima M, et al. Rho-kinase inhibitor upregulates migration by altering focal adhesion formation via the akt pathway in colon cancer cells. Eur J Pharmacol, 2011, 650: $145-150$

[23] Akagi Y, Liu W, Xie K, et al. Regulation of vascular endothelial growth factor expression in human colon cancer by interleukin-1beta. Br J Cancer, 1999, 80: 1506-1511.

[24] Bunger S, Haug U, Kelly M, et al. A novel multiplex-protein array for serum diagnostics of colon cancer: A case-control study. BMC Cancer, 2012, 12: 393.

[25] Cacev T, Loncar B, Seiwerth S, et al. Vascular endothelial growth factor polymorphisms $-1154 \mathrm{~g} / \mathrm{a}$ and $-460 \mathrm{c} / \mathrm{t}$ are not associated with vegf mrna expression and susceptibility to sporadic colon cancer. DNA Cell Biol, 2008, 27: 569-574.

[26] Cascinu S, Graziano F, Catalano V, et al. Differences of vascular endothelial growth factor (VEGF) expression between liver and abdominal metastases from colon cancer. Implications for the treatment with vegf inhibitors. Clin Exp Metastasis, 2000, 18: 651-655. 